\title{
Role of vitamin $D$ derivatives in intestinal tissue of patients with inflammatory bowel diseases
}

\author{
Maria Martinesi ${ }^{a}$, Stefano Ambrosini ${ }^{a}$, Cristina Treves ${ }^{a}$, Ulrich Zuegel ${ }^{b}$, \\ Andreas Steinmeyer $^{c}$, Vito Annese ${ }^{d}$, Monica Milla ${ }^{e}$, \\ Andrea G. Bonanomi ${ }^{d}$, Maria Stio ${ }^{a, *}$
}

a Department of Biomedical, Experimental and Clinical Sciences, University of Florence, Viale Morgagni 50, 50134 Florence, Italy

${ }^{b}$ Clinical Sciences, Global Biomarker, Global Discovery, Bayer Healthcare, Bayer, 10178 Berlin, Germany

c Medicinal Chemistry, Global Drug Discovery, Bayer Healthcare, Bayer, 10178 Berlin, Germany

'Division of Gastroenterology 2, Careggi Hospital, 50134 Florence, Italy

e Regional Referral Center for IBD, Careggi Hospital, 50134 Florence, Italy

Received 14 October 2013; received in revised form 7 February 2014; accepted 7 February 2014

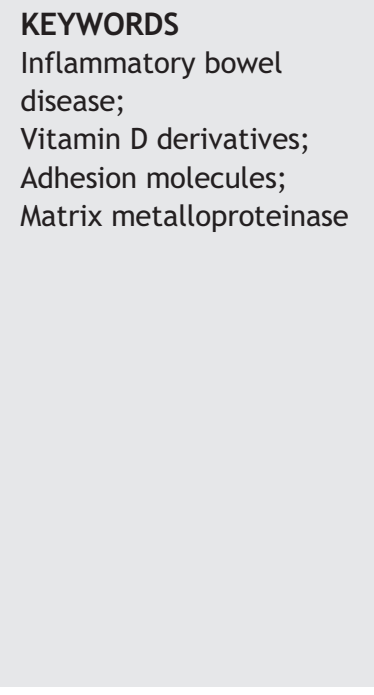

\begin{abstract}
Background and aim: The adhesion molecule expression and matrix metalloproteinases (MMPs) are proposed to be major factors for intestinal injury mediated by $T$ cells in (IBD) and are up-regulated in intestinal mucosa of IBD patients. To investigate the effect of vitamin D derivatives on adhesion molecules and MMPs in colonic biopsies of IBD patients.

Methods: Biopsies from inflamed and non-inflamed tract of terminal ileum and colon and PBMC from the same IBD patients were cultured with or without vitamin D derivatives. MMP activity and adhesion molecule levels were determined.

Results: $1,25(\mathrm{OH})_{2} \mathrm{D}_{3}$ and ZK 191784 significantly decrease ICAM-1 protein levels in the biopsies obtained only from the inflamed region of intestine of UC patients, while MAdCAM-1 levels decrease in the presence of $1,25(\mathrm{OH})_{2} \mathrm{D}_{3}$ in the non-inflamed region, and, in the presence of $\mathrm{ZK}$, in the inflamed one. In CD patients $1,25(\mathrm{OH})_{2} \mathrm{D}_{3}$ and ZK decrease ICAM- 1 and MAdCAM- 1 in the biopsies obtained from the non-inflamed and inflamed regions, with the exception of ICAM- 1 in the inflamed region in the presence of $1,25(\mathrm{OH})_{2} \mathrm{D}_{3}$. The expression of MMP-9, MMP-2, and MMP-3 decreases in the presence of vitamin $D$ derivatives in $U C$ and $C D$ with the exception of $1,25(\mathrm{OH})_{2} \mathrm{D}_{3}$ that does not affect the levels of MMP-9 and MMP-2 in CD. Vitamin D derivatives always affect MMP-9, MMP-2 and ICAM-1 in PBMC of UC and CD patients.
\end{abstract}

\footnotetext{
* Corresponding author. Tel.: + 390554598 330; fax: + 390554598905.

E-mail address: maria.stio@unifi.it (M. Stio).
} 
Conclusions: Based on the increased expression of ICAM-1, MAdCAM-1 and MMP-2,-9,-3 in IBD, our study suggests that vitamin $D$ derivatives may be effective in the management of these diseases.

(c) 2014 European Crohn's and Colitis Organisation. Published by Elsevier B.V. All rights reserved.

\section{Introduction}

Crohn's disease (CD) and ulcerative colitis (UC) are the two main phenotypes of inflammatory bowel diseases (IBD), which are chronically relapsing intestinal inflammatory conditions, associated with a disregulation of the mucosal immune system. ${ }^{1,2}$ A complex inflammatory cascade is responsible for the development and chronicity of the lesions, and in both CD and UC an increased production of proinflammatory cytokines is associated with the initiation and progression of the disease. ${ }^{3,4}$ In the areas of chronic mucosal inflammation and ulcerations of the gut wall a key role is played by various metalloproteinases (MMPs), which serve as effectors of cell migration, cytotoxicity and tissue remodelling via degradation of ECM components. MMPs, which are influenced by many proinflammatory cytokines ${ }^{5,6}$ are therefore proposed to be major factors for intestinal injury mediated by T cells in IBD. ${ }^{7}$ The activity of MMPs is strictly regulated by their natural inhibitors, the tissue inhibitors of MMPs (TIMPs). ${ }^{8} \mathrm{~A}$ disturbance of the regulated balance between MMPs and TIMPs has been implicated in the pathogenesis of IBD. ${ }^{9}$

Among MMPs, MMP-2 and MMP-9 (gelatinase A and B) are endoproteases, which, upon activation, mediate immune cell extravasation via proteolysis of basement membranes. ${ }^{10,11}$ MMP-2, most commonly expressed enzyme in normal tissue, is primarily produced by stromal cells, while MMP-9 is mainly synthesized by inflammatory cells, particularly by polymorphonuclear leucocyte. ${ }^{12}$ MMP-9 plays a key role in the pathogenesis of inflammatory diseases and it has been found to be up-regulated in immune cells during active flares of IBD in humans. ${ }^{7,13}$ Pedersen et al. ${ }^{14}$ reported that mRNA levels for MMP-3 and MMP-9 were increased significantly in colonic epithelial cells from inflamed areas compared with macroscopic non-inflamed areas, taken in parallel from the same patient. Therefore, in chronic inflammation, inhibition of MMP-activities may be desired. In addition to their direct effects on ECM, there is evidence that MMPs are also involved in the recruitment of inflammatory cells into the intestine. ${ }^{15,16}$ Several studies have examined the expression of mucosal adhesion molecules in chronic IBD, showing that intracellular adhesion molecules play an important role in the recruitment of leucocytes at sites of inflammation and are up-regulated in intestinal mucosa of IBD patients. ${ }^{17}$ In IBD, lymphocyte infiltration into the intestinal tract is mainly mediated by the interaction between $\alpha_{4} \beta_{7}$ integrin, expressed on lymphocytes, and its specific ligand mucosal addressin CAM-1 (MAdCAM-1), expressed on the endothelial cells of the microvasculature in the inflamed intestinal tract. Vedolizumab is a selective humanized lgG1 monoclonal antibody against $\alpha 4 \beta 7$ integrin resulting in a specific blockade of gut-homing lymphocytes. Of interest, recently Sandborn et al. ${ }^{18}$ have conducted integrated induction and maintenance trials of vedolizumab, in patients with moderately to severely active $C D$. Vedolizumab-treated patients with active $C D$ were more likely than patients receiving placebo to achieve the remission. Similarly, Feagan et al. ${ }^{19}$ have conducted two integrated randomized, doubleblind, placebo-controlled trials of vedolizumab in patients with active UC, and reported that vedolizumab was more effective than placebo for induction and maintenance of remission. Intercellular adhesion molecule-1 (ICAM-1) is an inducible transmembrane glycoprotein of the immunoglobulin family that is constitutively expressed on vascular endothelial cells and on a subset of leucocytes. Inflammatory cytokines, such as TNF- $\alpha$ and IL-1, induce the presence of ICAM-1, of selectin, and probably also of MAdCAM-1 on the endothelium in inflamed tissue. ${ }^{20}$ Moreover, the expression of ICAM-1 in CD is increased not only in the intestinal mucosa but also in the submucosa and in the muscle layers. ${ }^{21}$ ICAM-1 has also been shown to increase in the serum of IBD patients, correlating with disease activity. ${ }^{22,23}$ Molecules that block interactions between adhesion molecules present on circulating immune cells and their endothelial cell receptors could decrease the migration of these cells through the endothelium and, therefore, decrease chronic inflammation. The hormonally active form of vitamin D, 1,25-dihydroxyvitamin $D_{3}\left[1,25(\mathrm{OH})_{2} D_{3}\right]$ exerts its action by binding to the vitamin $\mathrm{D}$ receptor (VDR), an inducible transcription factor that influences the transcription of various genes, whose products are also involved in the regulation of the immune response ${ }^{24}$ in many experimental autoimmune diseases, among which IBD, where systemic therapy with $1,25(\mathrm{OH})_{2} \mathrm{D}_{3}$ results in significant inhibition of disease symptoms, or prevention of disease onset. ${ }^{25}$ Vitamin $\mathrm{D}$ may protect against the development of IBD. Several studies suggest that these effects may be partly mediated by genetic variants of VDR. In fact, several polymorphisms have been identified in VDR gene, however, their role in the predisposition to UC and $C D$ is conflicting. ${ }^{26}$ Moreover, a link between vitamin $D$ availability, either from sunshine or diet, and the prevalence of IBD has been reported. ${ }^{27}$ In addition, vitamin D deficiency is common in patients with IBD. ${ }^{28}$

In our previous studies the immunosuppressive role of vitamin $\mathrm{D}$ derivatives in IBD, and their potential therapeutic role was reported. ${ }^{29-32}$ New vitamin D analogues with selective immunoregulatory properties and lower hypercalcemic effects than those of $1,25(\mathrm{OH})_{2} \mathrm{D}_{3}$ have been developed. One of these is ZK 191784 (ZK), characterised by a 22,23-double bond, 24R-hydroxy group, 25-cyclopropyl ring, and 5-butyloxazole unit, which shows a therapeutic advantage over $1,25(\mathrm{OH})_{2} \mathrm{D}_{3}$ by inducing immunosuppressive effects also at concentrations that do not cause hypercalcemia. ${ }^{33}$ This vitamin $D$ analogue competitively binds to VDR with a similar affinity as $1,25(\mathrm{OH})_{2} \mathrm{D}_{3}$, inhibits antigen-induced lymphocyte proliferation and cytokine secretion "in vitro" and displays a unique tissue-specific profile when administered "in vivo". ${ }^{34}$ Moreover, in experimental colitis induced in mice by dextran sodium sulphate, ZK demonstrated significant anti-inflammatory properties that were at least partially mediated by its immunosuppressive effects on mucosal dendritic cells. ${ }^{35}$ It would be 
therefore relevant to test the action of both $1,25(\mathrm{OH})_{2} \mathrm{D}_{3}$ and ZK 191784 in biopsies obtained from the un-inflamed and inflamed areas of the intestine of IBD patients.

The aim of the present study was to demonstrate whether the vitamin $D$ derivatives down-regulate adhesion molecules and decrease MMP production in biopsies of IBD patients, suggesting therefore that these molecules may represent $\mathrm{a}$ potential target for the treatment of IBD.

\section{Materials and methods}

\subsection{Patients}

After obtaining informed consent for this study from all patients, biopsies were taken at routine diagnostic colonoscopies from patients with IBD. Seven CD patients (four men and three women with a mean age of 49.2, range 37-67 yr old), seven UC patients (four men and three women with a mean age of 48.0 , range $31-65 \mathrm{yr}$ old) with active disease, and five healthy subjects (three men and two women with a mean age of 52.5 range $44-66 \mathrm{yr}$ old) were studied. The healthy controls were selected in an age range similar to that of patients, among subjects undergoing endoscopic screening for colon cancer prevention. The diagnosis of $C D$ and UC was established on the basis of clinical symptoms and on endoscopic, histological, radiological demonstration and pathologic criteria, as described by Lennard-Jones. ${ }^{36}$ UC and $C D$ were defined according to the Montreal classification. ${ }^{37}$ These data are reported in Tables 1 and 2. Biopsy samples were taken from (I) inflamed and (NI) non-inflamed area. The histological assessments at biopsies sites confirmed the severity of inflammation.

In E1 UC patients, samples were taken from I: rectum and $\mathrm{NI}$ : sigmoid colon.

In E2 patients, samples were taken from I: rectum and sigmoid colon and $\mathrm{NI}$ : from transverse colon.

In E3 patients, samples were taken from I: rectum and transverse colon and NI: from caecum or ascending colon.

IN CD patients, number 1, 2, 3 and 5 (I) biopsies were taken from the inflamed terminal ileum. In $C D$ patients number 4, 6, and 7 (I) biopsies were taken from the inflamed colon. NI biopsies were taken from the non-inflamed colonic mucosa. CD patients with perianal or proximal disease were not included in the present study.

Table 1 Definition of ulcerative colitis phenotype according to the Montreal classification.

\begin{tabular}{lllll}
\hline Pts & Sex & Age & E & S \\
\hline 1 & $M$ & 31 & E3 & S2 \\
2 & $M$ & 64 & E3 & S2 \\
3 & $M$ & 32 & E1 & S2 \\
4 & F & 33 & E3 & S2 \\
5 & $M$ & 52 & E3 & S2 \\
6 & F & 65 & E3 & S2 \\
7 & F & 59 & E2 & S2 \\
\hline
\end{tabular}

Abbreviations:

Pts $=$ Patients, $\mathrm{S}=$ Sex, $\mathrm{A}=$ Age at the time of the sampling, $\mathrm{E}=$ Maximal Extent at any time, $S=$ Severity.
Table 2 Definition of Crohn's disease phenotype according to the Montreal classification.

\begin{tabular}{llllll}
\hline Pts & Sex & Yrs & A & L & B \\
\hline 1 & M & $46(26)$ & A2 & L3 & B2 \\
2 & M & $37(13)$ & A1 & L3 & B1 \\
3 & M & $45(19)$ & A2 & L3 & B1 \\
4 & F & $67(41)$ & A3 & L2 & B1 \\
5 & F & $66(42)$ & A3 & L1 & B2 \\
6 & F & $39(18)$ & A2 & L2 & B1 \\
7 & M & $44(23)$ & A2 & L2 & B1 \\
\hline
\end{tabular}

Abbreviations:

Pts = Patients, $\mathrm{S}=$ Sex, Yrs = Years at the time of sampling (and at diagnosis), $\mathrm{A}=$ Age at diagnosis, $\mathrm{L}=$ Location, $\mathrm{B}=$ Behaviour.

PBMC were obtained by the same patients, from which colonic biopsies were taken.

\subsection{Materials}

RPMI 1640 medium Hepes modification, PBS, heat inactivated FBS, L-glutamine and antibiotics were obtained from Sigma (St. Louis, MO). $1 \times 10^{-2}$ M ZK 191784 in ethanol was a generous gift from Bayer Schering Pharma Aktiengesellschaft. $1,25(\mathrm{OH})_{2} \mathrm{D}_{3}$ in isopropanol was a generous gift from $\mathrm{Dr}$. Lise Binderup (Leo Pharmaceutical Products). Stock solutions were stored at $-20{ }^{\circ} \mathrm{C}$, protected from light and freshly diluted in culture medium before each experiment. VDR, ICAM-1, MAdCAM-1, MMP-3 and $\beta$-actin antibodies, and horseradish peroxidaseconjugated secondary antibodies were obtained from Santa Cruz Biotechnology (California, USA). All other chemicals were the highest grade available from E. Merck (Darmstadt, Germany), Sigma (St. Louis, MO), and Bio-Rad Laboratories.

\subsection{PBMC isolation and culture conditions}

PBMC were obtained from UC and CD patients by density gradient (1.077) centrifugation (30 $\mathrm{min}$ at $400 \times \mathrm{g}$ ) of heparinized venous blood diluted 1:2 with PBS on Ficoll-Paque. About 95\% of mononuclear cells at the interface, containing PBMC, was collected and washed twice with PBS. Viability of PBMC was determined by Trypan blue exclusion test. The cells were always viable in all the experimental conditions used.

Biopsies and PBMC $\left(2 \times 10^{6}\right.$ cells $)$ were cultured for $24 \mathrm{~h}$ and $48 \mathrm{~h}$, respectively, in RPMI 1640 supplemented with $25 \mathrm{mM}$ Hepes, 10\% (v/v) heat inactivated FBS, $60 \mathrm{mg} / \mathrm{l}$ $(100 \mathrm{U} / \mathrm{ml})$ penicillin, $100 \mathrm{mg} / \mathrm{l}$ streptomycin, $0.29 \mathrm{~g} / \mathrm{l}$ L-glutamine, and incubated in the presence of vehicle alone or $100 \mathrm{nM} 1,25(\mathrm{OH})_{2} \mathrm{D}_{3}$ or $1 \mu \mathrm{M}$ ZK. PBMC were incubated with $10 \mu \mathrm{g} / \mathrm{ml}$ PHA used alone or in association with $100 \mathrm{nM}$ $1,25(\mathrm{OH})_{2} \mathrm{D}_{3}$ or $1 \mu \mathrm{M}$ ZK. The cultures were maintained at $37{ }^{\circ} \mathrm{C}$ in a humidified atmosphere containing $5 \% \mathrm{CO}_{2}$. At the end of the incubation with the compounds the medium was collected and used for the determination of MMP activity (MMP-9 and MMP-2). Biopsies and PBMC, collected by scraping adherent monocytes, were homogenized in lysis buffer (10 mM Hepes, $150 \mathrm{mM} \mathrm{NaCl}, 1 \mathrm{mM}$ EDTA 0.6\% NP-40, $0.5 \mathrm{mM}$ PMSF, $1 \mu \mathrm{g} / \mathrm{ml}$ leupeptin, $1 \mu \mathrm{g} / \mathrm{ml}$ aprotinin, and $0.5 \mu \mathrm{g} / \mathrm{ml}$ pepstatin). The homogenate was centrifuged at $10,000 \times g$ for $15 \mathrm{~min}$ at $4{ }^{\circ} \mathrm{C}$, and the supernatant was used for protein determination and Western blot analysis. 


\subsection{Protein determination}

Protein concentration was determined by the Bradford method, ${ }^{38}$ using bovine serum albumin as standard.

\subsection{Western blot analysis}

Total cell lysates from intestinal biopsies and PBMC were prepared and equal proteins were electrophoresed on SDS 10\% polyacrylamide gel. Electrophoresed proteins were transferred onto pure PVDF membranes (Bio-Rad Laboratories), as reported by Laemmli. ${ }^{39}$ After transfer, the membranes were washed with TPBS at room temperature, incubated overnight at $4{ }^{\circ} \mathrm{C}$ with the opportune primary antibody (VDR or ICAM-1 or MAdCAM-1 or MMP-3), washed again, and then incubated for $60 \mathrm{~min}$ with the relative secondary antibody. The membranes, after three washes with TPBS, were treated with the chemiluminescent substrate and enhancer (ECL or ECL plus, Amersham). Blots were analysed by Chemi-Doc (Bio-Rad) utilising the Quantity One programme (Bio-Rad). Protein bands were normalized using the respective $\beta$-actin protein band. Densitometric data are given relative to vehicle, set equal to 100 .

\subsection{Zymography}

MMP-9 and MMP-2 gelatinase activity was visualised by zymography. Briefly, SDS polyacrylamide gels $(8 \%)$ containing $0.1 \%$ gelatine were overlaid with $4 \%$ stacking gels. Sample supernatants were mixed (10:1 volume) with a sample buffer consisting of $50 \mathrm{mM}$ Tris- $\mathrm{HCl}$, pH 6.8, $2 \%$ SDS, $20 \%$ glycerol, and $0.03 \%$ bromophenol blue. After the loading of the samples, electrophoresis was carried out at $125 \mathrm{~V}$ for $2 \mathrm{~h}$. After electrophoresis, the gels were soaked in $2.5 \%$ Triton X-100 on a shaker for $1 \mathrm{~h}$, at room temperature, changing the solution after $30 \mathrm{~min}$, to eliminate SDS. The gels were then equilibrated for $30 \mathrm{~min}$ with the digestion buffer $(50 \mathrm{mM}$ Tris- $\mathrm{HCl}$, $\mathrm{pH} 7.5,5 \mathrm{mM} \mathrm{CaCl}, 200 \mathrm{mM} \mathrm{NaCl}$ ) at room temperature with gentle agitation, then replaced with fresh digestion buffer and incubated at $37{ }^{\circ} \mathrm{C}$ overnight. The gels were then stained for $1-2 \mathrm{~h}$ with $0.5 \%$ Coomassie Brilliant Blue in $30 \%$ methanol and $10 \%$ acetic acid and destained with 30\% methanol and 10\% acetic acid, after which clear bands of digested gelatine were clearly visible. The gels were scanned by Chemi-Doc (Bio-Rad), utilising the Quantity One programme (Bio-Rad).

\subsection{Statistical methods}

Statistical significance was determined by either one-way ANOVA followed by a Bonferroni $t$ test or by a Student's $t$-test. One-way analysis of variance was used to determine significance among groups, after which the modified $t$ test with the Bonferroni correction was used for comparison between individual groups. Differences were considered significant at $P<0.05$.

\subsection{Ethical consideration}

The study was approved by the Medical Ethics Committee, CE 2 maggio 2011, protocol 0016888, rif. 95/10 (Division of Gastroenterology 2, Careggi Hospital, 50134
Florence, Italy). Informed consent was obtained from all subjects.

\section{Results}

\section{1. $1,25(\mathrm{OH})_{2} \mathrm{D}_{3}$ and $\mathrm{ZK} 191784$ influence VDR protein levels in intestinal biopsies of HS, UC and $C D$ patients}

The effects of $1,25(\mathrm{OH})_{2} \mathrm{D}_{3}$ (D) and ZK 191784 (ZK) on VDR protein levels in intestinal biopsies of HS, UC and CD patients are depicted in Fig. 1. With the exception of the incubation with $1,25(\mathrm{OH})_{2} \mathrm{D}_{3}$ in biopsies obtained from the non-inflamed intestinal region of $C D$ patients, in all the other cases a significant increase in VDR protein levels is registered in the presence of $1,25(\mathrm{OH})_{2} \mathrm{D}_{3}$ or $\mathrm{ZK}$, the highest values being obtained in biopsies of healthy subjects.

\section{2. $1,25(\mathrm{OH})_{2} \mathrm{D}_{3}$ and $\mathrm{ZK} 191784$ influence ICAM-1 and MAdCAM-1 protein levels in intestinal biopsies of HS, UC and CD patients}

The effects of $1,25(\mathrm{OH})_{2} \mathrm{D}_{3}$ (D) and ZK 191784 (ZK) on ICAM-1 and MAdCAM-1 protein levels in intestinal biopsies of HS, UC and $C D$ patients are depicted in Fig. 2 (A, B, C, respectively).

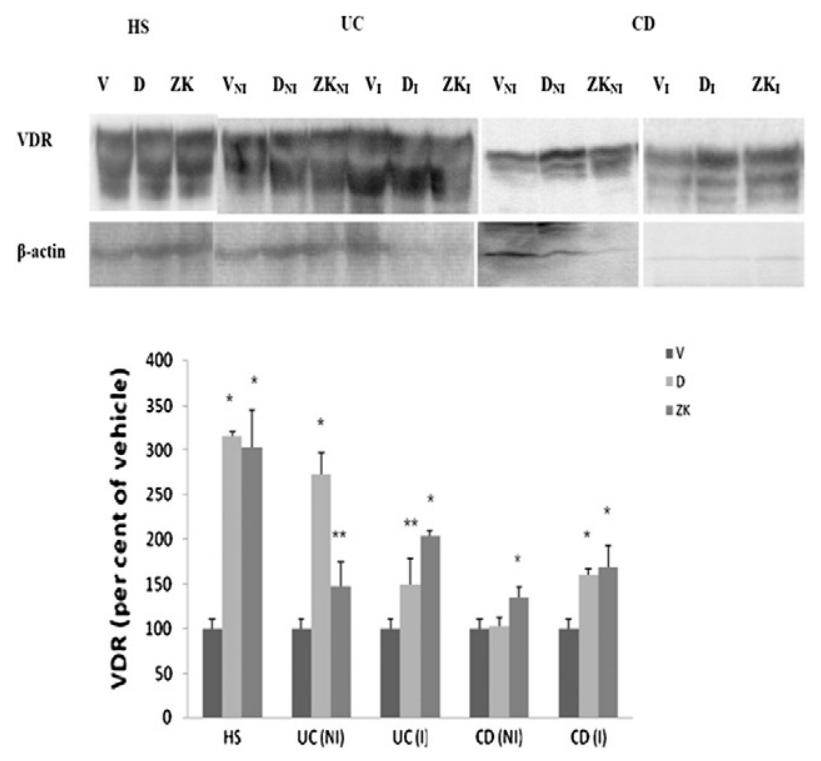

Figure 1 Effects of vitamin D derivatives on VDR. VDR protein levels were determined by Western blot analysis in intestinal biopsies obtained from healthy subjects (HS) and from noninflamed (NI) and inflamed (I) intestinal regions of ulcerative colitis (UC) and Crohn's disease (CD) patients after 24-h incubation with $100 \mathrm{nM} 1,25(\mathrm{OH})_{2} \mathrm{D}_{3}$ (D) or $1 \mu \mathrm{M}$ ZK 191784 (ZK). The densitometric values, normalized with the use of the respective $\beta$-actin protein band, are reported as the percentage of the cells treated with vehicle alone $(\mathrm{V})$. The vehicle was represented by the culture medium with ethanol or isopropanol at the same concentration used in the experiments with vitamin $D$ derivatives. Each densitometric value represents the mean \pm S.D. of three separate experiments. ${ }^{* *} P<0.05$ (in comparison with vehicle alone). ${ }^{*} P<0.01$ (in comparison with vehicle alone). 
In HS (Fig. 2A) $1,25(\mathrm{OH})_{2} \mathrm{D}_{3}$ does not influence ICAM-1 protein levels, which, on the contrary, are significantly decreased by the incubation with ZK. Both $1,25(\mathrm{OH})_{2} \mathrm{D}_{3}$ and ZK remarkably decrease MAdCAM-1 protein levels.

From Fig. 2B, it may be observed that, in UC patients, neither $1,25(\mathrm{OH})_{2} \mathrm{D}_{3}$ nor $\mathrm{ZK}$ induce a decrease on ICAM-1 protein levels in the biopsies obtained from the non-inflamed region of intestine, but $1,25(\mathrm{OH})_{2} \mathrm{D}_{3}$ induce a slight increase. On the contrary these levels are significantly decreased by these two vitamin D derivatives in the inflamed region. MAdCAM-1 protein levels decrease in the presence of $1,25(\mathrm{OH})_{2} \mathrm{D}_{3}$ in the non-inflamed region, and of $\mathrm{ZK}$ in the inflamed one. This decrease is particularly accentuated in the inflamed region in the presence of ZK, while ZK induces a slight increase on NI tract. The comparison between ICAM-1 levels determined in biopsies obtained from non-inflamed and inflamed regions of intestine and incubated with vehicle alone (Table 3) indicates that these levels are higher in the inflamed region in comparison with the non-inflamed one, with an increase of about $545 \%$. The increase in MAdCAM-1 levels in the inflamed region compared with the non- inflamed one is about $150 \%$.

In CD patients (Fig. $2 \mathrm{C}$ ), both $1,25(\mathrm{OH})_{2} \mathrm{D}_{3}$ and $\mathrm{ZK}$ decrease the levels of ICAM-1 and MAdCAM-1 in the biopsies obtained from the non-inflamed and inflamed regions, with the exception of ICAM-1 in the inflamed region, which is not affected
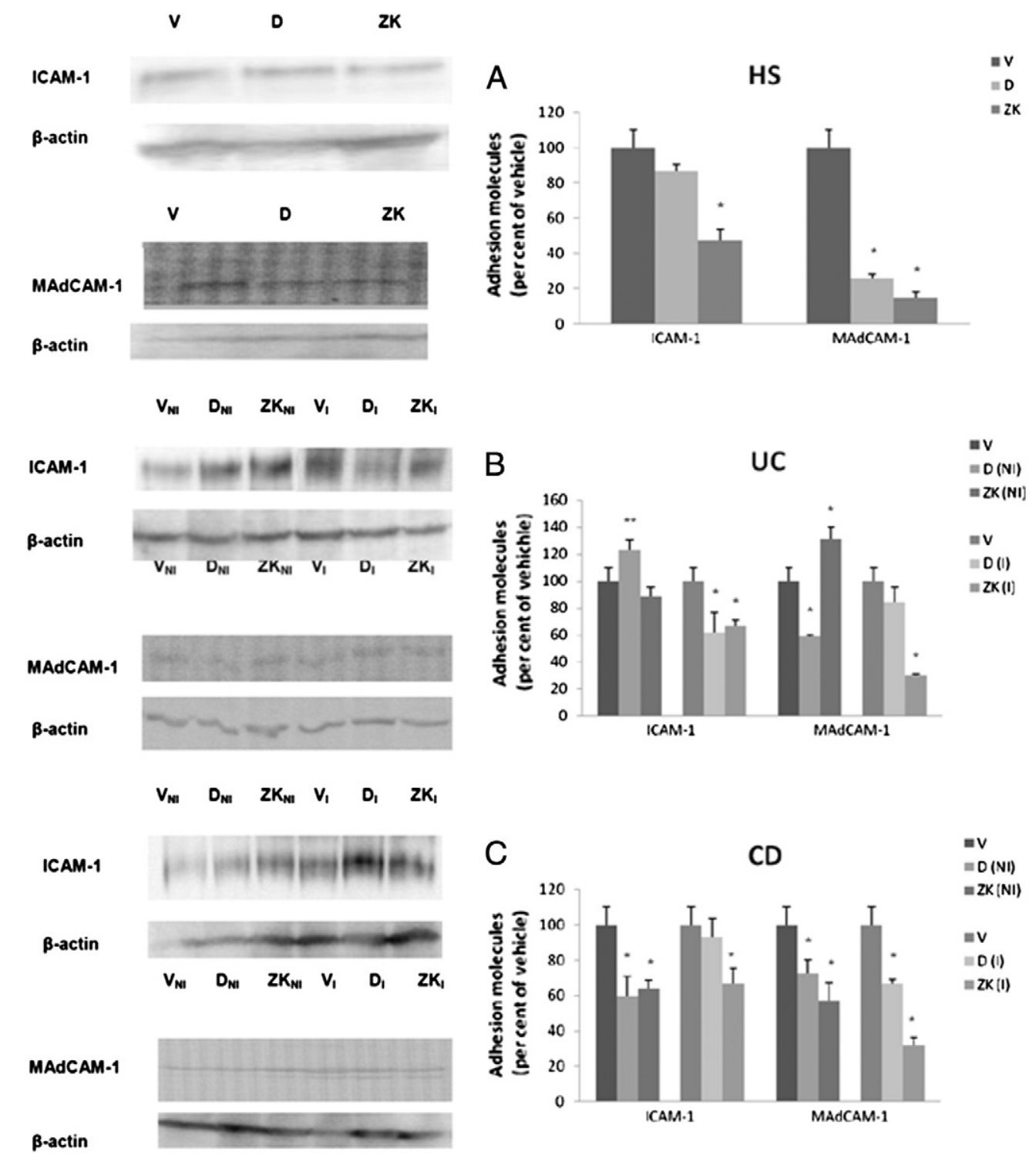

Figure 2 A, B and C: Effects of vitamin D derivatives on ICAM-1 and MAdCAM-1. ICAM-1 and MAdCAM-1 protein levels were determined by Western blot analysis in intestinal biopsies obtained from healthy subjects (HS) (A) and from non-inflamed (NI) and inflamed (I) intestinal regions of ulcerative colitis (UC) (B) and Crohn's disease (CD) (C) patients after 24-h incubation with 100 nM $1,25(\mathrm{OH})_{2} \mathrm{D}_{3}$ (D) or $1 \mu M$ ZK 191784 (ZK). The densitometric values, normalized with the use of the respective $\beta$-actin protein band, are reported as the percentage of the cells treated with vehicle alone $(\mathrm{V})$. The vehicle was represented by the culture medium with ethanol or isopropanol at the same concentration used in the experiments with vitamin $D$ derivatives. Each densitometric value represents the mean \pm S.D. of three separate experiments. ${ }^{* *} P<0.05$ (in comparison with vehicle alone). ${ }^{*} P<0.01$ (in comparison with vehicle alone). 
by the incubation with $1,25(\mathrm{OH})_{2} \mathrm{D}_{3}$. The highest inhibition is observed in the inflamed region for MAdCAM-1 in the presence of ZK. Here the comparison between ICAM-1 levels, determined in biopsies obtained from non-inflamed and inflamed regions (Table 3 ) of intestine and incubated with vehicle alone, shows that these levels are higher in the inflamed region in comparison with the non-inflamed one, with an increase of about $300 \%$. The increase in MAdCAM-1 levels in the inflamed region compared with the non-inflamed one is of about $175 \%$.

\section{3. $1,25(\mathrm{OH})_{2} \mathrm{D}_{3}$ and $\mathrm{ZK} 191784$ influence ICAM-1 protein levels in PBMC of UC and CD patients}

The results, reported in Fig. 3, indicate that ICAM-1 levels significantly decrease when PBMC of both UC and CD patients were incubated with vitamin $D$ derivatives compared to the cell stimulated with PHA alone.

\section{4. $1,25(\mathrm{OH})_{2} \mathrm{D}_{3}$ and $\mathrm{ZK} 191784$ influence metalloproteinase protein levels in intestinal biopsies of HS, UC and CD patients}

In $\mathrm{HS}$ (Fig. 4A) $1,25(\mathrm{OH})_{2} \mathrm{D}_{3}$ is able to significantly decrease MMP-3 levels, while it is ineffective on MMP-9 and MMP-2. On the contrary, all the MMP studied decreased after the treatment of the biopsies with ZK, this effect being particularly remarkable for MMP-9.

In UC, Fig. 4B, with the exception of MMP-3 levels determined in the non-inflamed region, which are not influenced by $1,25(\mathrm{OH})_{2} \mathrm{D}_{3}$, all the other determinations indicate that both $1,25(\mathrm{OH})_{2} \mathrm{D}_{3}$ and ZK significantly decrease the levels of the MMPs under study. This effect is always noteworthy in the presence of ZK. Indeed, the levels of MMP-9 in the noninflamed region were undetectable, when ZK was present.

From Fig. 4C, which depicts the results obtained with the biopsies of CD patients, it may be observed that $1,25(\mathrm{OH})_{2} \mathrm{D}_{3}$ does not affect the levels of MMP-9 and MMP-2, while it significantly decreases those of MMP-3. On the other hand, ZK always decreases the levels of the three MMPs in the non-inflamed region and in the inflamed one.

The comparison between MMP levels determined in biopsies obtained from non-inflamed and inflamed regions of intestine obtained from UC and CD patients incubated with vehicle alone shows that these levels are higher in the inflamed region in comparison with the non-inflamed one. The results are reported in Table 3.

Table 3 Values of MMPs, adhesion molecules and VDR vehicles from the inflamed tracts of UC and CD patients, referred to the non-inflamed ones, set equal to 100 .

\begin{tabular}{lllllll}
\hline Patients & MMP-9 & MMP-2 & MMP-3 & ICAM-1 & Mad-CAM & VDR \\
\hline UC & 800 & 325 & 190 & 545 & 150 & 62 \\
CD & 500 & 290 & 480 & 300 & 175 & 44
\end{tabular}

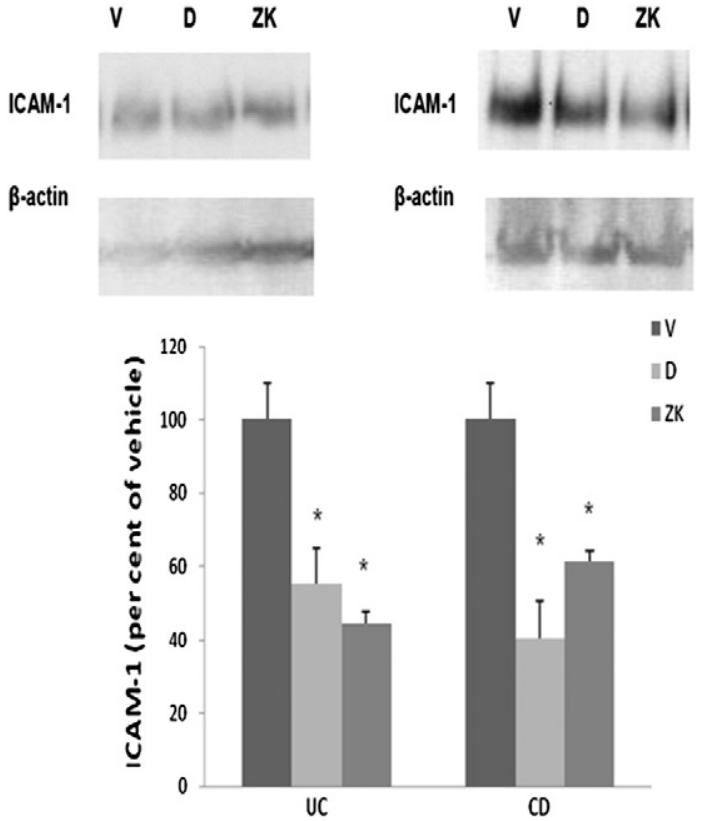

Figure 3 Effects of vitamin D derivatives on ICAM-1. ICAM-1 protein levels were determined by Western blot analysis in PBMC obtained from ulcerative colitis (UC) and Crohn's disease (CD) patients after $48 \mathrm{~h}$ incubation with $100 \mathrm{nM} 1,25(\mathrm{OH})_{2} \mathrm{D}_{3}$ (D) or $1 \mu \mathrm{M}$ ZK 191784 (ZK). The densitometric values, normalized with the use of the respective $\beta$-actin protein band, are reported as the percentage of the cells treated with vehicle alone $(\mathrm{V})$. The vehicle was represented by the culture medium with ethanol or isopropanol at the same concentration used in the experiments with vitamin $D$ derivatives. Each densitometric value represents the mean \pm S.D. of three separate experiments. ${ }^{*} P<0.01$ (in comparison with vehicle alone).

\section{5. $1,25(\mathrm{OH})_{2} \mathrm{D}_{3}$ and $\mathrm{ZK} 191784$ influence metalloproteinase in PBMC of UC and CD patients}

The levels of MMP-9 and MMP-2, released in the culture medium by PBMC obtained from UC and CD patients, are reported in Fig. 5. The results obtained indicate that MMP-9 and MMP-2 production by PBMC of both UC and CD patients significantly decreases incubating the cells with the vitamin $D$ derivatives. The highest decrease is observed for MMP-9 incubating the cells with ZK in UC patients.

\section{Discussion}

IBD are characterised by high intestinal turnover during the sequence of inflammation, tissue destruction and healing. Recruitment of cells to diseased intestinal mucosa is essential to the initiation and perpetuation of IBD. The recruitment involves activation of a number of adhesion molecules and their ligands on leucocytes and vascular endothelium. MAdCAM-1 plays a central role in the aetiology of IBD through its ability to direct circulating lymphocytes to enter gutassociated lymphoid tissue and gut interstitium.

In this study we examined the action of $1,25(\mathrm{OH})_{2} \mathrm{D}_{3}$ and the vitamin D analogue ZK 191784 on biopsies obtained from 


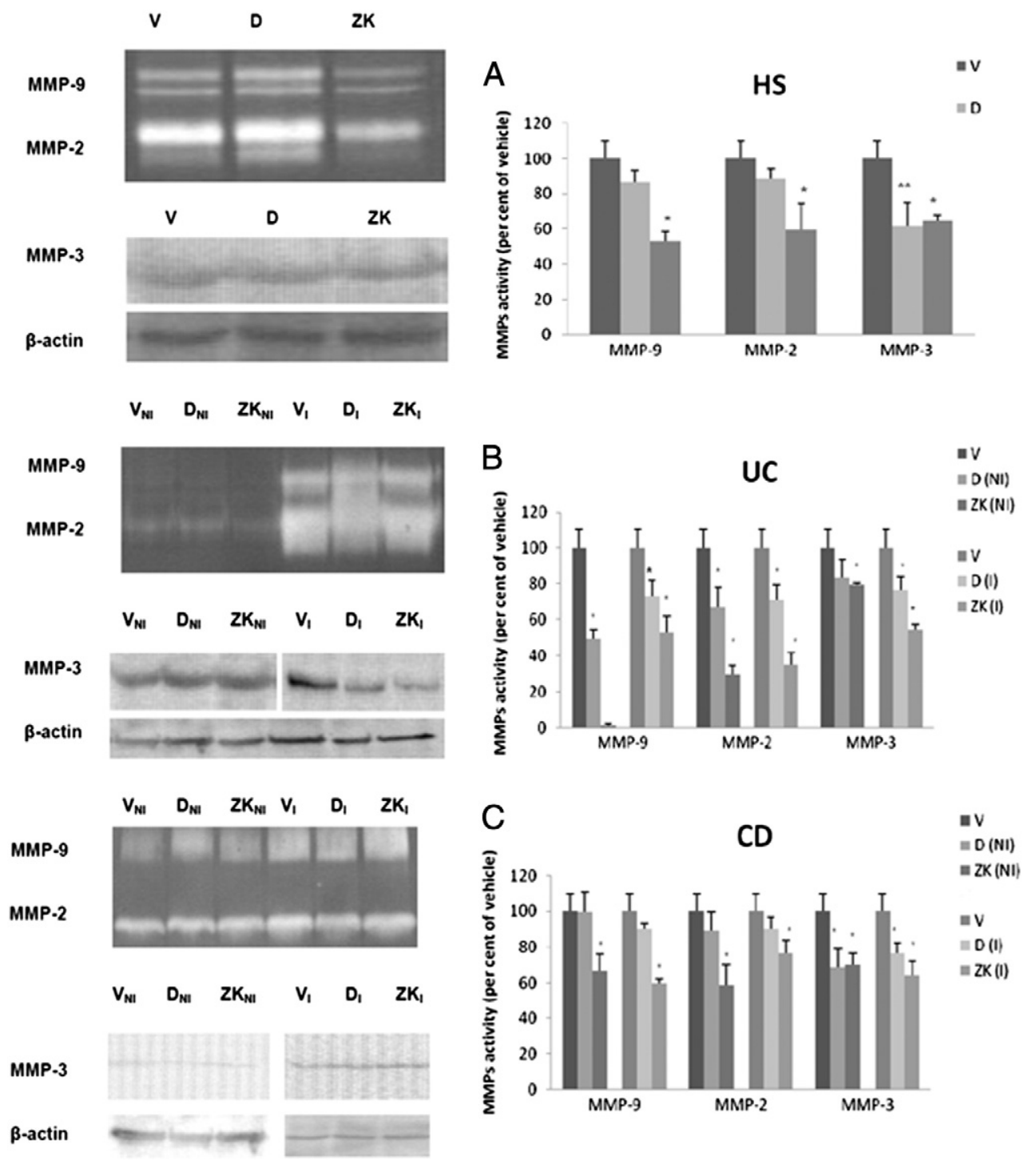

Figure 4 A, B and C: Effects of vitamin D derivatives on MMPs. Activity of MMP-9, and MMP-2 was measured by zymography, MMP-3 protein levels were determined by Western blot analysis in intestinal biopsies obtained from healthy subjects (HS) (A) and from non-inflamed (NI) and inflamed (I) intestinal regions of ulcerative colitis (UC) (B) and Crohn's disease (CD) (C) patients after $24 \mathrm{~h}$ incubation with $100 \mathrm{nM} \mathrm{1,25(OH)})_{2} \mathrm{D}_{3}$ (D) or $1 \mu \mathrm{M} \mathrm{ZK} 191784(\mathrm{ZK})$. The densitometric values are reported as the percentage of the cells treated with vehicle alone $(\mathrm{V})$. The vehicle was represented by the culture medium with ethanol or isopropanol at the same concentration used in the experiments with vitamin D derivatives. Each densitometric value represents the mean \pm S.D. of three separate experiments. ${ }^{* *} P<0.05$ (in comparison with vehicle alone). ${ }^{*} P<0.01$ (in comparison with vehicle alone).

non-inflamed and inflamed tract of gut of UC and CD patients, with the aim to verify whether these substances could decrease ICAM-1 and MAdCAM-1 levels. Our data indicate that such levels are remarkably higher in the inflamed tract in comparison with the non-inflamed one, confirming the data reported in literature. ${ }^{40}$ Our results were homogeneous despite the different sites of biopsy sampling (terminal ileum and colon), being only dependent on the activity of the disease (inflamed vs non inflamed areas). We have reported also the data obtained from colonic biopsies of healthy subjects in order to verify whether the response to the investigated markers could be different comparing healthy subjects with non-inflamed tract of IBD patients.
The effect of vitamin D derivatives was also tested on MMP (MMP-9,-2,-3) expression that we have previously shown to increase in PBMC of IBD patients and to decrease in the presence of the vitamin D analogue ZK 156979. ${ }^{32}$

The vitamin D derivatives, in particular the $Z K$, seem to be effective in blocking the expression of adhesion molecules responsible of inflammatory effects in IBD, thus suggesting that ZK may be considered for further clinical development as potential effective in the treatment of IBD.

In order to reduce ICAM-1 protein expression, the use in therapy of ISIS-2302, a 20-base phosphorothioate antisense oligodeoxynucleotide, was suggested in steroid refractory Crohn's disease. Following the initial positive results, ${ }^{21}$ two 


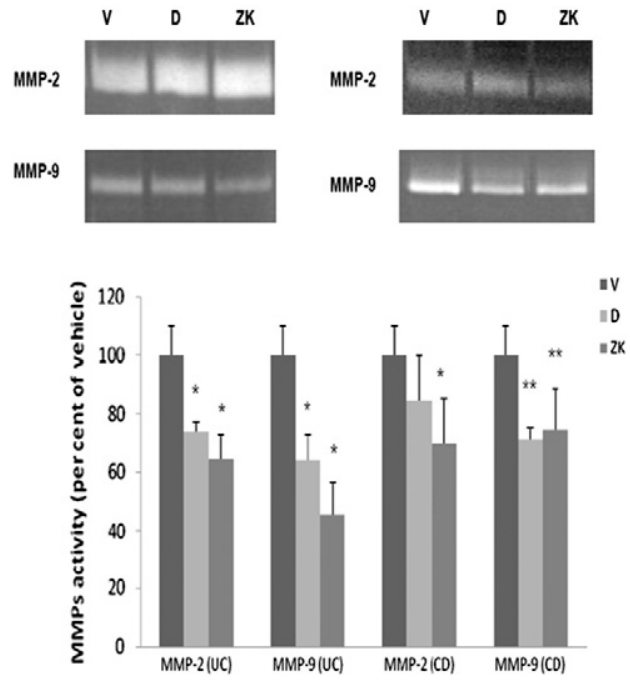

Figure 5 Effects of vitamin D derivatives on MMP-2 and MMP-9. Activity of MMP-2 and MMP-9 was measured by zymography on culture medium of PBMC obtained from ulcerative colitis (UC) and from Crohn's disease (CD) after $48 \mathrm{~h}$ culture with $100 \mathrm{nM} 1,25(\mathrm{OH})_{2} \mathrm{D}_{3}$ (D) or $1 \mu \mathrm{M}$ ZK 191784 (ZK). PBMC. The densitometric values are reported as the percentage of the cells treated with vehicle alone (V). The vehicle was represented by the culture medium with ethanol or isopropanol at the same concentration used in the experiments with vitamin $D$ derivatives. Each densitometric value represents the mean \pm S.D. of three separate experiments. ${ }^{* *} P<0.05$ (in comparison with vehicle alone). ${ }^{*} P<0.01$ (in comparison with vehicle alone).

subsequent placebo-controlled trials failed to demonstrate the efficacy.

The concomitant inhibitory effect of about $50 \%$ that we have reported, on both colonic biopsies and PBMC, is interesting and suggests a possible way to detect the clinical efficacy and the inflammatory status in vitro.

This inhibitory effect may be mediated by the inhibition of TNF- $\alpha$ production, similar to that we observed for PBMC in IBD patients. ${ }^{32}$ Indeed, we have previously demonstrated that the vitamin D analogue ZK 156979 down-regulates TNF- $\alpha$ production by PBMC, and this decrease could be effective in the inhibition of the MMP activities and adhesion molecules, both increased in colonic mucosa and PBMC of IBD patients. In addition, other authors have shown an up-regulation of MMPs and ICAM-1 in intestinal tissue of patients with IBD with a significant improvement after administration of the anti-TNF- $\alpha$ antibody infliximab. ${ }^{41,21}$

The inhibitory effect on adhesion molecules is a genomic effect mediated by VDR, whose level increases when the biopsies are incubated with ZK, suggesting that ZK exerts its effects by binding to VDR.

Recently Lees et al. ${ }^{42}$ have reported that Hedgehog $(\mathrm{Hh})$ signalling through Gli1 is required for appropriate modulation of the intestinal response to acute inflammatory challenge. Reduced Gli1 function predisposes to a heightened myeloid response to inflammatory stimuli, potentially leading to IBD. The functional relevance of Gli1 is demonstrated by the severe intestinal inflammation that develops in the face of a $50 \%$ reduction in Gli1 concentration in an established mouse model of colitis.

Moreover, Uhmann et al. ${ }^{43}$ report an increased Hh pathway activity in the Patched Mouse Model of Embryonal Rhabdomyosarcoma (ERMS) and demonstrate that the treatment with the active form of vitamin $D_{3}$, calcitriol, inhibits Hh signalling and proliferation of murine ERMS in vivo and in vitro.

Concomitantly, calcitriol activates VDR signalling and induces tumour differentiation. These authors suggest that exogenous supply of calcitriol could be beneficial in the treatment of rhabdomyosarcoma, the most common soft tissue sarcoma in children, especially in those associated with aberrant Hh signalling activity.

In the present study we have demonstrated that vitamin $D$ derivatives affect adhesion molecules and MMP activating VDR signalling, but we have not investigated if this effect is genetically determined, implicating the Hedgehog $(\mathrm{Hh})$ signalling. Some authors ${ }^{44}$ report that vitamin D decreases GI2 expression in tumours without detecting VDR in total protein extracts from tumours, thus dissociating the possible activity of vitamin $D_{3}$ on human clear renal cell carcinoma (CCC) through VDR.

The inhibitory effect, exerted by the vitamin $D$ derivatives on both colonic mucosa and PBMC, is relevant, as vitamin D is supposed to exert a role in IBD. Moreover a recent study reports a correlation between MMP-9 serum activity and the activity of disease. ${ }^{45}$ This correlation could be useful in the prediction of $C D$ activity status, as the intensity of the disease process in intestinal tract is reflected by MMP concentrations in the blood. Therefore, the vitamin $D$ derivatives could be potentially utilised for controlling the disease activity and the inflammation. The impact of this research is interesting, as other authors ${ }^{46}$ observed that serum concentration of MMP-9 was significantly higher in UC and CD patients compared with controls.

Many MMPs, including MMP-2 and MMP-9 are highly expressed in inflamed tissue of IBD patients. MMP-9 is produced by epithelial cells during experimental colitis. ${ }^{47}$ MMP-9 null mice have a less severe colitis in response to the administration of dextran sodium sulphate, thus suggesting that the blocking of MMP-9 may be of potential therapeutic benefit in IBD. ${ }^{47}$

Many studies have demonstrated that several MMP inhibitors significantly reduce tissue injury in animal models of inflammatory bowel disease, ${ }^{48-51}$ indicating that MMP inhibitors may be candidates for the treatment of IBD.

Among the numerous MMPs, MMP-9 may be considered a key enzyme responsible for accelerated breakdown of ECM in UC, because its expression is higher in patients with UC in comparison with controls. ${ }^{12}$ These data are in agreement with those reported in this study in which MMP levels were higher in the inflamed regions of intestine in comparison with the non-inflamed ones. Other authors have reported that MMP-2 and MMP-9 are enhanced in intestinal tissue and seem to be actively involved in the inflammatory and remodelling processes in $\mathrm{IBD}$, without major differences between $C D$ and UC. ${ }^{9}$ Our results that report a significantly inhibitory effect on MMP-9 and MMP-2 in colonic biopsies of IBD patients are in accordance with those obtained in PBMC of UC and CD patients.

Also MMP-3 is important in the tissue environment for migration of CD4+ T lymphocytes into the lamina propria. ${ }^{52}$ Endothelial cells can make MMP-3, and there is a possibility 
that, when an intestine-homing CD4 + cell binds to a MAdCAM-1 positive vessel in the colon, it signals the endothelial cells to release MMP-3 into the pericellular space to open up tight junctions, allowing the lymphocytes to migrate through. We have demonstrated that vitamin $D$ derivatives may affect also MMP-3.

In conclusion, based on the increased expression of ICAM-1, MAdCAM-1 and MMP-2,-9,-3, in the inflamed areas of the gut of IBD patients and the inhibitory effects of vitamin $D$ derivatives as we found in the present study, we hypothesize that adhesion molecules and MMPs are potential targets of vitamin $D$ derivatives with possible efficacy in the management of these diseases.

\section{Author contributions}

Maria Stio designed the study, collected and analysed the data and wrote the paper. Maria Martinesi and Stefano Ambrosini performed the majority of experiments; Ulrich Zuegel and Andreas Steinmeyer provided the vitamin D analogue ZK 191784; Vito Annese, Monica Milla and Andrea $\mathrm{G}$. Bonanomi provided the collection of all the biopsies that were taken from healthy subjects and from patients with IBD at routine diagnostic colonoscopies. Cristina Treves, who extensively studied the action of vitamin $D$ derivatives, was interested in this research. Vito Annese revised the final version of the article which was approved by all the authors.

\section{Conflict of interest}

The authors have no conflict of interest.

\section{Acknowledgements}

We are grateful for the collaboration to the "Centro di Riferimento per le Malattie Croniche Intestinali" of Florence (Italy). This study was supported by grants from MIUR.

\section{References}

1. van Assche G. Emerging drugs to treat Crohn's disease. Expert Opin Emerg Drugs 2007;12:49-59.

2. Peyrin-Biroulet L, Desreumaux P, Sandborn WJ, Colombel JF. Crohn's disease: beyond antagonists of tumour necrosis factor. Lancet 2008;372:67-81.

3. Stevens C, Walz G, Singaram C, Lipman B, Zanker A, Muggia D, et al. Tumor necrosis factor-alpha, interleukin-1-beta and interleukin-6 expression in inflammatory bowel disease. Dig Dis Sci 1992; 37:818-26.

4. Mûzes G, Molnár B, Tulassay Z, Sipos F. Changes of the cytokine profile in inflammatory bowel diseases. World J Gastroenterol 2012;18:5848-61.

5. Kovacs EJ, DiPietro LA. Fibrogenic cytokines and connective tissue production. FASEB J 1994;8:854-61.

6. Birkedal-Hansen H, Moore WG, Bodden MK, Windson LJ, Birkedal-Hansen B, DeCarlo A, et al. Matrix metalloproteinases: a review. Crit Rev Oral Biol Med 1993;4:197-250.

7. Pender SL, Tickle SP, Docherty AJ, Howie D, Wathen NC, MacDonald TT. A major role for matrix metalloproteinases in T cell injury in the gut. J Immunol 1997;158:1582-90.
8. Murphy G, Reynolds JJ, Royce PM, Steinmann B. Connective tissue and its heritable disorders: molecular, genetic, and medical aspects. In: Murfy G, editor. Extracellular matrix degradation. New York: Wiley-Liss, Inc.; 1993. p. 287-316.

9. von Lampe B, Barthel B, Coupland SE, Riecken EO, Rosewicz S. Differential expression of matrix metalloproteinases and their tissue inhibitors in colon mucosa of patients with inflammatory bowel disease. Gut 2000;47:63-73.

10. Leppert D, Hauser SL, Kishiyama JL, An S, Zeng L, Goetzl EJ. Stimulation of matrix metalloproteinase-dependent migration of T cells by eicosanoids. FASEB J 1995;9:1473-81.

11. Leppert D, Waubant E, Galardy R, Bunnett NW, Hauser SL. T cell gelatinases mediate basement membrane transmigration in vitro. J Immunol 1995;154:4379-89.

12. Gao Q, Meijer MJ, Kubben FJ, Sier CF, Kruidenier L, van Duijn $\mathrm{W}$, et al. Expression of matrix metalloproteinases-2 and -9 in intestinal tissue of patients with inflammatory bowel diseases. Dig Liver Dis 2005; 37:584-92.

13. Kirkegaard T, Hansen A, Bruun E, Brynskov J. Expression and localisation of matrix metalloproteinases and their natural inhibitors in fistulae of patients with Crohn's disease. Gut 2004;53: 701-9.

14. Pedersen G, Saermark T, Kirkegaard T, Brynskov J. Spontaneous and cytokine induced expression and activity of matrix metalloproteinases in human colonic epithelium. Clin Exp Immunol 2009;155:257-65.

15. Girard JP, Springer TA. High endothelial venules [HEVs]: specialized endothelium for lymphocyte migration. Immunol Today 1995;16:449-57.

16. Springer TA. Traffic signals for lymphocyte recirculation and leukocyte emigration: the multistep paradigm. Cell 1994;76: 301-14.

17. Nakamura S, Ohtani $\mathrm{H}$, Watanabe $\mathrm{Y}$, Fukuscima $\mathrm{K}$, Matsumoto $\mathrm{T}$, Kitano A, et al. In situ expression of the cell adhesion molecules in inflammatory bowel disease. Evidence of immunologic activation of vascular endothelial cells. Lab Invest 1993;69:77-85.

18. Sandborn WJ, Feagan BG, Rutgeerts P, Hanauer S, Colombel JF, Sands BE, et al. Vedolizumab as induction and maintenance therapy for Crohn's disease. N Engl J Med 2013;369:711-21.

19. Feagan BG, Rutgeerts $P$, Sands BE, Hanauer S, Colombel JF, Sandborn WJ, et al. Vedolizumab as induction and maintenance therapy for ulcerative colitis. N Engl J Med 2013;369: 699-710.

20. Bernstein CN, Sargent M, Gallatin WM. Deta2-integrin/ICAM expression in Crohn's disease. Clin Immunol Immunopathol 1998; 86:147-60.

21. Van Assche G, Rutgeerts P. Physiological basis for novel drug therapies used to treat the inflammatory bowel disease. I. Immunology and therapeutic potential of antiadhesion molecule therapy in inflammatory bowel disease. Am J Physiol Gastrointest Liver Physiol 2005;288:G169-74.

22. Jones SC, Banks RE, Haidar A, Gearing AJ, Hemingway IK, Ibbotson $\mathrm{SH}$, et al. Adhesion molecules in inflammatory bowel disease. Gut 1995;36:724-30.

23. Nielsen $\mathrm{OH}$, Langholz E, Hendel J, Brynskov J. Circulating soluble intercellular adhesion molecule-1 (sICAM-1) in active inflammatory bowel disease. Dig Dis Sci 1994;39:1918-23.

24. Brown AJ. Regulation of vitamin D action. Nephrol Dial Transplant 1999;14:11-6.

25. Cantorna MT, Mahon BD. Mounting evidence for vitamin D as an environmental factor affecting autoimmune disease prevalence. Exp Biol Med 2004;229:1136-42.

26. Xue LN, Xu KQ, Zhang W, Wang Q, Wu J, Wang XY. Associations between vitamin $\mathrm{D}$ receptor polymorphisms and susceptibility to ulcerative colitis and Crohn's disease: a meta-analysis. Inflamm Bowel Dis 2013;19:54-60.

27. Deluca HF, Cantorna MT. Vitamin D: its role and uses in immunology. FASEB J 2001;15:2579-85. 
28. Cantorna MT. Vitamin D, and autoimmunity: is vitamin D status an environmental factor affecting autoimmune disease prevalence? Proc Soc Exp Biol Med 2000;223:230-3.

29. Stio M, Treves C, Celli A, Tarantino O, d'Albasio G, Bagnoli S, et al. Synergistic inhibitory effect of cyclosporin $A$ and vitamin $D$ derivatives on T-lymphocyte proliferation in active ulcerative colitis. Am J Gastroenterol 2002;97:680-9.

30. Stio M, Treves C, Martinesi M, d'Albasio G, Bagnoli S, Bonanomi AG. Effect of anti-TNF therapy and vitamin D derivatives on the proliferation of peripheral blood mononuclear cells in Crohn's disease. Dig Dis Sci 2004;49:328-35.

31. Martinesi M, Treves C, d'Albasio G, Bagnoli S, Bonanomi AG, Stio M. Vitamin $D$ derivatives induce apoptosis and downregulate ICAM-1 levels in peripheral blood mononuclear cells of inflammatory bowel disease patients. Inflamm Bowel Dis 2008;14:597-604.

32. Martinesi M, Treves C, Bonanomi AG, Milla M, Bagnoli S, Zuegel $U$, et al. Down-regulation of adhesion molecules and matrix metalloproteinases by ZK156979 in inflammatory bowel diseases. Clin Immunol 2010;136:51-60.

33. Zügel U, Steinmeyer A, Giesen C, Asadullah K. A novel immunosuppressive $1 \alpha, 25$-dihydroxyvitamin $D_{3}$ analogue with reduced hypercalcemic activity. J Invest Dermatol 2002;119: 1434-42.

34. Nijenhuis $T$, van der Eerden BCJ, Zügel U, Steinmeyer A, Weinans $\mathrm{H}$, Hoenderop JG, et al. The novel vitamin D analog ZK 191784 as an intestine-specific vitamin D antagonist. FASEB $J$ $2006 ; 20: 2171-3$.

35. Strauch UG, Obermeier F, Grunwald N, Dunger N, Rath, Schölmerich J, et al. Calcitriol analog ZK191784 ameliorates acute and chronic dextran sodium sulphate-induced colitis by modulation of intestinal dendritic cell numbers and phenotype. World J Gastroenterol 2007;13:6529-37.

36. Lennard-Jones JE. Classification of inflammatory bowel disease. Scand J Gastroenterol 1989;24:2-6.

37. Mowat C, Cole A, Windsor A, Ahmad T, Arnott I, Driscoll R, et al. Guidelines for the management of inflammatory bowel disease in adults. Gut 2011;60:571-607.

38. Bradford MM. A rapid and sensitive method for the quantitation of microgram quantities of protein utilizing the principle of protein-dye binding. Anal Biochem 1976;72:248-54.

39. Laemmli UK. Cleavage of structural proteins during the assembly of the head of bacteriophage T4. Nature 1970;227: $680-5$.

40. Ala A, Dhillon AP, Hodgson HJ. Role of cell adhesion molecules in leukocyte recruitment in the liver and gut. Int J Exp Pathol 2003;84:1-16.
41. Meijer MJ, Mieremet-Ooms MA, van Duijn W, van der Zon AM, Hanemaaijer R, Verheijen $\mathrm{JH}$, et al. Effect of anti-tumor necrosis factor-alpha antibody infliximab on the ex vivo mucosal matrix metalloproteinase-proteolytic phenotype in inflammatory bowel disease. Inflamm Bowel Dis 2007;13:200-10.

42. Lees CW, Zacharias WJ, Tremelling M, Noble CL, Nimmo ER, Tenesa A, et al. Analysis of germline GLI1 variation implicates hedgehog signalling in the regulation of intestinal inflammatory pathways. PLoS Med 2008; 5:e239.

43. Uhmann A, Niemann H, Lammering B, Henkel C, Heß I, Rosenberger $A$, et al. Calcitriol inhibits hedgehog signaling and induces Vitamin $D$ receptor signaling and differentiation in the patched mouse model of embryonal rhabdomyosarcoma. Sarcoma 2012;2012:1-7.

44. Dormoy V, Béraud C, Lindner V, Coquard C, Barthelmebs M, Brasse D, et al. Vitamin D3 triggers antitumor activity through targeting hedgehog signaling in human renal cell carcinoma. Carcinogenesis 2012;33:2084-93.

45. Kofla -Dlubacz A, Matusiewicz M, Krystek-Korpacka M, Iwanczak B. Correlation of MMP-3 and MMP-9 with Crohn's disease activity in children. Dig Dis Sci 2012;57:706-12.

46. Lakatos G, Hritz I, Varga MZ, Juhász M, Miheller P, Cierny G, et al. The impact of matrix metalloproteinases and their tissue inhibitors in inflammatory bowel diseases. Dig Dis 2012;30: 289-95.

47. Castaneda FE, Walia B, Vijay-Kumar M, Patel NR, Roser S, Kolachala VL, et al. Targeted deletion of metalloproteinase 9 attenuates experimental colitis in mice; central role of epithelialderived MMP. Gastroenterology 2005;129:1991-2008.

48. Di Sebastiano P, di Mola FF, Artese L, Rossi C, Mascetta G, Pernthaler $\mathrm{H}$, et al. Beneficial effects of Batimastat (BB-94), a matrix metalloproteinase inhibitor, in rat experimental colitis. Digestion 2001;63:234-9.

49. Medina C, Videla S, Radomski A, Radomski MW, Antolin M, Guarner $\mathrm{F}$, et al. Increased activity and expression of matrix metalloproteinase-9 in rat model of distal colitis. Am J Physiol Gastrointest Liver Physiol 2003;284:G116-22.

50. Naito Y, Takagi T, Kuroda M, Katada K, Ichikawa H, Kokura S, et al. An orally active matrix metalloproteinase inhibitor, ONO-4817, reduces dextran sulfate sodium-induced colitis in mice. Inflamm Res 2004;53:462-8.

51. Yamada A, Uegaki A, Nakamura T, Ogawa K. ONO-4817, an orally active matrix metalloproteinase inhibitor, prevents lipopolysaccharide-induced proteoglycan release from the joint cartilage in guinea pigs. Inflamm Res 2000;49:144-6.

52. Naito $Y$, Yoshikawa $T$. Role of matrix metalloproteinases in inflammatory bowel disease. Mol Aspects Med 2005;26:379-90. 